\title{
A SEXUALIDADE NA FORMAÇÃO ACADÊMICA DO ENFERMEIRO
}

\author{
The sexuality on nurses' academic training \\ La sexualidad en la formación académica del enfermero
}

\author{
Graciela Dutra Sehnem ${ }^{1}$ \\ Fernanda Machado da Silva ${ }^{4}$
}

Lúcia Beatriz Ressel

Carolina Frescura Junges ${ }^{3}$

Camila Nunes Barreto ${ }^{5}$

\section{RESUMO}

Este estudo teve como objetivo analisar como se dá a construção da sexualidade na formação acadêmica de estudantes de Enfermagem. Foi realizado com 14 estudantes de um curso de graduação em Enfermagem do Rio Grande do Sul. 0 método caracterizou-se por pesquisa descritiva, com abordagem qualitativa. Os dados foram coletados pela técnica do grupo focal no período de maio a junho de 2009. Para a sua interpretação foi aplicada a análise temática. No que tange à formação acadêmica do enfermeiro em relação à sexualidade, esse assunto tem sido tratado a partir de um caráter de eventualidade e informalidade e abordado sob um enfoque de neutralidade, proibições e assexualização. Recomenda-se que a sexualidade seja tratada como assunto de estudo na Enfermagem e como fenômeno inerente a todo o ser humano.

Palavras-chave: Sexualidade. Estudantes de Enfermagem. Enfermagem.

\begin{abstract}
This study aimed to analyze how sexuality is built up in the academic studies of Nursing students. It was developed with 14 students from a Nursing Graduation Course in Rio Grande do Sul. The method was characterized by a descriptive research with qualitative approach. The data was collected through the focus group technique in the period of May and June 2009. The theme analysis was applied in order to interpret the data. Concerning the nurse academic studies towards sexuality, this topic has been discussed from a character of event and informality and approached from a perspective of neutrality, prohibitions and sterilization. It is recommended that sexuality is treated as a nursing study topic and an inherent phenomenon to every human being.
\end{abstract}

Keywords: Sexuality. Nursing Students. Nursing.

\section{Resumen}

Ese estudio tuvo como objetivo analizar cómo ocurre la construcción de la sexualidad en la formación académica de estudiantes de Enfermería. Fue realizado con 14 estudiantes de un Curso de Graduación en Enfermería en Rio Grande de Sur. EI método se caracterizó por investigación descriptiva, con abordaje cualitativo. Los datos fueron recolectados por la técnica del grupo focal en el período de mayo a junio de 2009. Fue aplicado el análisis temático para la interpretación de estos. Sobre la formación académica del enfermero en relación a la sexualidad, ese asunto ha sido tratado a partir de un carácter de eventualidad e informalidad y abordado bajo un enfoque de neutralidad, prohibiciones y asexualización. Se recomienda que la sexualidad sea tratada como asunto de estudio en enfermería y como fenómeno inherente a todo ser humano.

Palabras Clave: Sexualidad. Estudiantes de Enfermería. Enfermería.

\footnotetext{
'Enfermeira. Doutoranda do Programa de Pós-Graduação em Enfermagem da UFRGS. Professora Assistente do Curso de Graduação em Enfermagem da Universidade Federal do Pampa (UNIPAMPA). Uruguaiana-RS. Brasil. E-mail: graci_dutra@yahoo.com.br; ${ }^{2}$ Enfermeira. Doutora, Professora Associada do Departamento de Enfermagem e do Programa de Pós-Graduação em Enfermagem (PPGEnf) da Universidade Federal de Santa Maria (UFSM). Líder do grupo de pesquisa: Cuidado, Saúde e Enfermagem e da Linha de pesquisa: Estudos culturais em cuidado, saúde e enfermagem da UFSM. Santa MariaRS. Brasil. E-mail: Ibressel208@yahoo.com.br; ${ }^{3}$ Enfermeira no setor de Emergência Adulto do Hospital Universitário da Universidade Federal de Santa

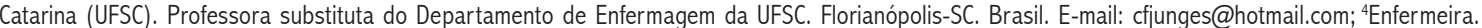
Mestre em Enfermagem Programa de Pós-Graduação em Enfermagem da UFSM. Professora Assistente do Curso de Graduação em Enfermagem da Universidade Federal do Pampa (UNIPAMPA). Uruguaiana-RS. Brasil. E-mail: fernandasilva@unipampa.edu.br; ${ }^{5}$ Acadêmica de Enfermagem da UFSM. Bolsista do Programa de Educação Tutorial (PET). Membro do grupo de pesquisa Cuidado, Saúde e Enfermagem e da Linha de pesquisa: Estudos culturais em cuidado, saúde e enfermagem da UFSM. Santa Maria-RS. Brasil. E-mail: camilabarreto_6@msn.com
} 


\section{INTRODUÇÃO}

Os estudos sobre sexualidade, relegados durante anos a ocuparem uma posição marginal no plano das ciências, multiplicaram-se de forma significativa a partir dos anos de 1980, com o surgimento da Síndrome da Imunodeficiência Adquirida (AIDS). Tais estudos, concebidos no campo da medicina preventiva, focalizaram, principalmente, o comportamento e as práticas sexuais, sendo estes delimitados pela noção de risco ${ }^{1}$. Essa perspectiva essencialista, que relacionou o estudo da sexualidade à genitalidade, ao ato sexual e à reprodução, ainda se mantém presente e predominante no enfoque dos estudos da área da saúde.

A sexualidade, quando concebida sob essa perspectiva e tratada como uma questão pontual, que precisa ser medicalizada ou orientada preventivamente, como um elemento ausente na dimensão do ser humano cuidado, e igualmente na dimensão do enfermeiro cuidador, reforça o modelo assexualizado do cuidado de enfermagem, sendo isto reproduzido, também, na formação dos enfermeiros ${ }^{1}$.

$\mathrm{Na}$ enfermagem, a sexualidade tem aparecido associada a tabus e preconceitos, que perpassam tanto a formação acadêmica quanto a prática profissional. É no momento do cuidado, a partir da interação dos corpos de quem o pratica e de quem o recebe, que a sexualidade ganha espaço para emergir. Porém, quando velada, pode consistir em mecanismo gerador de ansiedades, incertezas e constrangimentos mútuos.

Nesse sentido, compreende-se a necessidade de desvelar essa temática na formação acadêmica do enfermeiro, considerando que não há espaços de reflexão que tratem da sexualidade tanto dos estudantes de Enfermagem quanto do sujeito cuidado. Assim, ensina-se a cuidar de um corpo doente que não é sensual e nem sexual'.

Desse modo, acredita-se na necessidade de gerar espaços de discussão, na formação acadêmica deste profissional, que tratem a sexualidade como dimensão inerente ao ser humano, abordando-a principalmente no âmbito da subjetividade, que possibilita sua interpretação cultural. Para tanto, entende-se que a sexualidade é parte da construção sociocultural de todas as pessoas, independente do querer ou não delas, revelando-se por meio de gestos, discursos, atitudes, posturas, olhares, silêncios, enfim, no comportamento de cada pessoa, como um todo 1 .

Dessa forma, os estudantes de Enfermagem, ao compreenderem-se como seres sexuados e perceberem aqueles com quem interagem no processo de cuidar como tal, descobrem-se como fonte de emoção, tendo a possibilidade de sentir e produzir prazer no cuidado. Cabe ressaltar que isso poderá ser revertido em uma vivência mais contextualizada e qualitativa dessa dimensão humana ${ }^{3}$.

A oportunidade de discutir e refletir acerca da sexualidade configura uma possibilidade de instrumentalização dos estudantes para lidar com as diversas questões que a temática pode desencadear, bem como realizar o cuidado de enfermagem de forma mais tranquila, sensível e criativa ${ }^{3}$.

Além disso, a discussão da sexualidade na formação acadêmica constitui uma possibilidade de desconstruir e reconstruir conceitos e valores estabelecidos ao longo da vida dos indivíduos, como, por exemplo, o silêncio que envolve o tema, a recusa de informações, a manutenção do desconhecimento e as proibições repetidamente enfatizadas acerca da temática ${ }^{1}$. Isso pode se refletir na vida profissional, na assexualização do cuidado, na impessoalidade das relações, na ausência de diálogo, nas emoções e sentimentos contidos para não denotar o constrangimento, ao lidar com o corpo sexuado do outro, entre outras questões que podem vir à tona no momento do cuidado 3 .

A relevância desse estudo está em possibilitar a elaboração de subsídios que possibilitem reflexões singulares acerca da sexualidade, permitindo ressignificar conceitos na formação acadêmica e refletir acerca de preconceitos e tensões que permeiam essa temática. Além disso, busca-se contribuir para que a sexualidade, nesse momento de formação, seja percebida e vivenciada como mecanismo possibilitador da criatividade e da sensibilidade, tanto do sujeito que cuida quanto do que é cuidado.

Com base nessas considerações, utilizou-se como questão norteadora deste estudo: Como se dá a construção da sexualidade na formação acadêmica de estudantes de Enfermagem? Para responder a essa questão, o estudo objetivou analisar como se dá a construção da sexualidade na formação acadêmica de estudantes de Enfermagem.

\section{METODOLOGIA}

Trata-se de uma pesquisa qualitativa do tipo descritiva. Os sujeitos foram 14 estudantes, de ambos os sexos, com idade entre 19 e 23 anos, de um Curso de Graduação em Enfermagem de uma universidade pública do Rio Grande do Sul. Foram incluídos na pesquisa estudantes do curso de Enfermagem da instituição em que foi realizado o estudo, que estavam cursando, no período da coleta de dados, do terceiro ao oitavo semestres. A escolha do período acadêmico justifica-se pela inserção dos acadêmicos nas atividades práticas deste curso. Foram excluídos da pesquisa estudantes de Enfermagem que não estivessem incluídos nos semestres acima referidos, naquele período. Ressalta-se que, nesta pesquisa, a seleção dos sujeitos foi intencional, de acordo com os critérios de inclusão e objetivos do estudo.

Os dados foram coletados entre os meses de maio e junho de 2009. A produção dos dados fundamentou-se na técnica do grupo focal, que utiliza as sessões grupais como foros facilitadores da expressão de características psicossociológicas e culturais ${ }^{4}$. Esta técnica visa alcançar informações a partir do aprofundamento da interação entre os participantes, tanto para gerar consenso quanto para clarificar as divergências ${ }^{5}$. Deve ser propiciado um ambiente permissivo, 
no qual os participantes consigam expressar suas percepções, crenças, valores, atitudes e representações sociais sobre uma questão específica ${ }^{4}$.

Elaborou-se um guia de temas para o desenvolvimento das sessões grupais que auxiliou na discussão e na flexibilidade para ajustes ${ }^{6}$. Os temas perpassaram a forma como as questões relativas à sexualidade eram conduzidas nas aulas teóricas e práticas do curso de Enfermagem e os momentos da formação acadêmica em que tais questões eram abordadas.

Desenvolveram-se três encontros com grupos focais, nos quais participaram os sujeitos do estudo, um moderador e um observador. A composição do grupo considerou traços comuns que uniam os participantes, mas com suficiente variação entre eles para que aparecessem opiniões diferentes ou divergentes ${ }^{6}$. Como traços comuns, os participantes eram estudantes de Enfermagem da mesma instituição de ensino e vivenciarem aulas práticas no curso. Em relação à variação entre os participantes, integraram-se estudantes de ambos os sexos, pois a revelação de suas ideias enriqueceria a discussão do tema.

Cada encontro teve duração de duas horas, sendo possível atingir bons níveis de discussão $0^{6}$. Para o local das sessões foi escolhida uma sala de fácil acesso aos estudantes, confortável, com boa iluminação, ventilação e que assegurava a privacidade. Ainda, o preparo do local contou com o arranjo dos assentos em forma circular, de modo a promover a participação e propiciar uma boa interação face a face ${ }^{7}$. Para registrar as falas dos sujeitos utilizou-se um gravador digital, e, para registrar as observações, construiu-se um diário de campo.

A análise e a interpretação dos dados foram fundamentadas na análise temática, que operacionalmente foi realizada em três etapas, quais sejam: a pré-análise (primeira etapa); a exploração do material (segunda etapa); e 0 tratamento dos resultados obtidos e interpretação (terceira etapa) $)^{5}$.

Os princípios éticos da Resolução 196/96 do Conselho Nacional de Saúde foram observados ${ }^{8}$. A pesquisa foi aprovada pelo Comitê de Ética em Pesquisa da instituição a qual estava vinculada, sob o protocolo $n^{0} 23081.018415 / 2008-48$. A inserção dos participantes na pesquisa ocorreu mediante a assinatura do Termo de Consentimento Livre e Esclarecido. 0 anonimato dos sujeitos foi garantido por meio da utilização do sistema alfanumérico, demonstrado pela letra $\mathrm{S}$ seguida de números arábicos.

\section{RESULTADOS E DISCUSSÃO}

A partir da análise temática, emergiram das falas os seguintes temas: 0 caráter de eventualidade e informalidade em que a sexualidade era abordada na formação acadêmica; algumas normas e regras sociais relacionadas à construção histórica da profissão; e a neutralidade e a assexualização dos estudantes ao realizarem cuidados de enfermagem.
Na enfermagem, é possível evidenciar a carência de estudos e discussões em relação à sexualidade tanto em nível acadêmico quanto na prática profissional. Observa-se que estes, quando presentes, estão limitados à perspectiva biologicista e patologizante. A respeito disso, os depoimentos a seguir elucidam o caráter de eventualidade com que tem sido tratada a sexualidade, no contexto em que foi realizado o estudo, na formação acadêmica do enfermeiro.

Na nossa turma tivemos muito pontual, não teve uma abordagem específica sobre o tema. A professora estava, por exemplo, explicando um procedimento e salientava que tem que respeitar a sexualidade. (S1)

Durante os procedimentos, as professoras falaram alguma coisa de cuidar com a pessoa quando estiver dando o banho, fazendo algum procedimento. (S2)

É bem superficial, quase nada, quando estão explicando os procedimentos. A gente trabalhou, também, durante uma DCG [Disciplina Complementar de Graduação], que foi uma mestranda que conduziu com um texto sobre $o$ corpo, que, daísim, a gente pode expor, mas, antes, durante a graduação não. (S3)

A gente teve quando foi ter aula de banho de leito, foi a única parte do curso, até agora, que foi falado e foi muito superficial. A gente sentiu muita necessidade na prática de ter tido a teoria. (S13)

Não tem um dia para se falar da sexualidade tanto do paciente quanto do acadêmico, podia ter um momento específico só para isso. (S7)

De acordo com os relatos, as discussões acerca da sexualidade foram realizadas, na maioria das vezes, de forma eventual, associadas ao ensino de procedimentos que permitiram que 0 assunto viesse à tona. Percebe-se, também, que o tema foi abordado em uma disciplina complementar do curso, no qual foi associado à temática "corpo", o que é considerado de suma importância, uma vez que tais conceitos se inter-relacionam. Além disso, os estudantes ressaltam 0 desejo de discutir sobre a sua própria sexualidade e a do sujeito cuidado, pois entendem que isso servirá como subsídio para as vivências práticas do curso.

Cabe ressaltar que não discutir essa questão e as dificuldades sentidas em nível da graduação não isentará o enfermeiro de se deparar, futuramente, com a sua ocorrência durante a vida profissional. Ao contrário, acaba agravando, tornando as situações mais difíceis de serem resolvidas no dia a dia da prática do cuidado 9 . 
Esse contexto reforça a preocupação sobre como está se desenvolvendo a formação acadêmica do enfermeiro, uma vez que pode estar sendo reforçado o ocultamento da temática, o que constitui mecanismo gerador de sentimentos como a insegurança, a angústia e o constrangimento, no momento do cuidado de enfermagem. Tais reações negativas ou indesejadas remetem a questão do despreparo dos estudantes para lidar com a questão da sexualidade no cuidado ${ }^{10}$. Isso pode limitar a expressão da sensibilidade e da criatividade dos sujeitos envolvidos, nesse momento. Desse modo, nas situações em que o silêncio acerca da temática é a conduta adotada, perde-se a oportunidade não só de trabalhar os limites da interdição, mas também de repensar as perspectivas negativas que permeiam a temática ${ }^{1}$.

A partir dos relatos, também é possível perceber a condição de individualidade nas reflexões que tratam da sexualidade, ficando por conta de uma determinada área, disciplina ou professor. No entanto, é necessário estimular debates e estudos acerca desse tema na Enfermagem, o que pode ser revertido em dignidade, respeito e ética no cuidado'.

Dessa forma, ressalta-se a necessidade de aprofundamento das questões relativas à sexualidade humana nas disciplinas e conteúdos curriculares do curso de graduação em Enfermagem no qual a pesquisa foi desenvolvida. Fornecer conhecimentos específicos de forma a desmitificar o tema e reduzir os medos, os preconceitos e os constrangimentos do profissional, no momento em que ele desenvolve suas atividades, representa um benefício para o profissional e paciente ${ }^{11}$.

Os próximos relatos apontam, na realidade em que a pesquisa foi desenvolvida, para o caráter de informalidade que a temática assume na formação acadêmica do enfermeiro. Para tanto, os estudantes relatam que as discussões acerca da temática foram proporcionadas em atividades complementares, como, por exemplo, nos grupos de pesquisa. Dessa forma, menciona-se em algumas falas:

Especificamente no PET [Programa de Educação Tutorial] que a gente trabalhou mais aprofundado. (S1)

Se tu não te identifica com alguns grupos de pesquisa que trabalham isso, não é trabalhado na formação. (S3)

Eu não me lembro de nenhum momento que tenha marcado durante as aulas. Eu acho que são coisas extraclasses, nos grupos de pesquisa. Quando tu procura, consegue encontrar, mas no currículo não tem. (S5)

É importante considerar que esses espaços, embora específicos, concedidos para a discussão da temática, certamente proporcionam trocas de ideias e amadurecimento conceitual, que favorecem uma vivência mais salutar dessa dimensão humana no cuidado de enfermagem. No entanto, nas escolas de Enfermagem não há orientação de modo estrutural e sistemático em relação à abordagem da sexualidade. A discussão sobre a temática, durante a formação acadêmica do enfermeiro, aparece isolada e de forma pontual nos cursos de graduação, sendo viabilizada por iniciativas individuais ou de um grupo em particular ${ }^{12}$.

Assim, destaca-se que a falta de uma abordagem consistente com estudantes de Enfermagem, acerca do tema da sexualidade, pode prejudicá-los na sua futura prática diária, independente da sua área de atuação, considerando que podem não estar sendo preparados para tal. Com isso, aponta-se a necessidade da inserção dessa temática na grade curricular dos cursos de graduação em Enfermagem, envolvendo o corpo docente como um todo, tendo em vista a multidisciplinaridade do tema ${ }^{10}$.

Também, ressalta-se que a abordagem da sexualidade na formação acadêmica, pelos docentes, possibilita que os estudantes vivenciem de forma menos conflituosa sua própria sexualidade e que estejam informados e livres de preconceitos para realizarem o cuidado de pessoas com idades e necessidades de saúde diversas ${ }^{13}$.

Quanto à forma com que foi abordada a temática naquele contexto de formação acadêmica, os estudantes também destacaram algumas normas e regras sociais que foram enfocadas direcionando à apresentação pessoal dos alunos ao realizarem cuidados de enfermagem, num sentido de proibição. As próximas falas transmitem o controle sobre os modos de vestir, o que, sob a ótica dos estudantes, pode relacionar-se à própria construção histórica da profissão que está diretamente relacionada à forma de expressão da sexualidade de quem cuida. Assim revelam os depoimentos:

[...] historicamente a mulher tem sido considerada como inferior e a enfermagem, como uma profissão feminina, desenvolvida antes pelas prostitutas, ainda tem muito disso, inconscientemente. Por isso muitas vezes, a sexualidade da pessoa é barrada pela roupa [...]. É uma conquista de espaço da enfermagem, que busca se afirmar por esse comportamento certinho, e eu acho que não ébem por aí. (S3)

É muito marcante a questão do nosso cuidado físico. Isso é trabalhado desde o começo [do curso]: "Não usem decote, não pintem unha de vermelho." Isso é muito histórico, porque tem aquela questão da enfermagem como uma profissão feminina, e tem todos os preconceitos, que tu deve ser recatada, porque antes não era. É um cuidado importante, mas que às vezes padroniza muito. (S4) 
Quanto à construção histórica da Enfermagem, herdamos de Florence Nightingale não apenas a possibilidade de e mulher sair da esfera privada para a vida pública, mas também uma série de características que ainda hoje se fazem presentes nos discursos e nas práticas, antes essenciais para assegurarem uma nova imagem às enfermeiras. Ao iniciar a profissão, Florence preocupou-se em afastar a imagem das enfermeiras leigas, ressaltando, para tanto, a conduta moral das alunas, que deveria se apoiar em soluções corretivas por meio de mecanismos de controle. Para tanto, alicerçava-se em estratégias como o silenciar e o deserotizar o corpo da enfermeira ${ }^{14}$.

Para a alienação dos corpos das enfermeiras de seu conteúdo erótico, historicamente, utilizou-se o ensino e a realização perfeccionista e contínua das técnicas de enfermagem, enquanto ritual de neutralização e impessoalidade. Assim, as técnicas de enfermagem permitiriam a manipulação do corpo cuidado, não somente transformando o toque em um detalhe frio e repetitivo da técnica em si, mas também controlando a emoção, afastando a imagem da enfermeira como um corpo erotizado ${ }^{14}$. Desse modo, o procedimento técnico pode ser utilizado, pelo profissional, como uma estratégia para neutralizar a sexualidade, concretizando a assexualização de quem cuida e de quem é cuidado ${ }^{15}$.

No contexto do nascimento da Enfermagem moderna, as normas de conduta para as enfermeiras eram rígidas, sendo codificadas na austeridade da disciplina, na atenção aos pequenos detalhes do comportamento das enfermeiras, estendendo-se desde o controle dos movimentos corporais, uso de uniformes, tom de voz, forma de olhar, até a maneira de envolver-se com outras pessoas'.

Esses valores e normas interiorizados pela cultura, mesmo que de forma diferenciada, ainda persistem no cuidado de enfermagem. Isso pode ser percebido pelo controle das emoções, exaltação das técnicas, impessoalidade das relações, além de preocupações demasiadas com questões que perpassam os modos de vestir, agir e falar, que suscitam rituais de neutralização dos corpos sexuados ${ }^{1}$. Entende-se que essas questões presentes tanto no ensino quanto na prática de enfermagem são merecedoras de um olhar diferenciado, no intuito de rever significados construídos culturalmente e não torná-los habituais no cuidado de enfermagem.

Os próximos depoimentos reforçam a neutralidade e a assexualização, que os depoentes entendem que estão presentes no controle sobre a vestimenta e no comportamento dos estudantes para a realização das atividades práticas do curso. Isso é explicitado nas falas a seguir:

Falaram para a gente estar de branco, que não pode usar brinco e eu perguntei porquê. E responderam que é uma questão de organização, de higiene, que a gente se identifica porque usa branco, fica uma coisa mais organizada, mais parelha. (S3)

A gente é preparada para sair daqui, vestir uma roupa branca, tirar os brincos, prender o cabelo e entrar para o hospital e deixar a sexualidade do lado de fora, como se a gente entrasse no hospital e tivesse que deixar a nossa vida para o lado de fora. Tu não vai ser simplesmente uma enfermeira que vai deixar tua sexualidade e teus valores, $e$ isso não é trabalhado. (S5)

Para os participantes deste estudo, o fato de serem orientados a não usar adornos pessoais, a se uniformizar e manter os cabelos presos na ocasião da prestação de cuidados de enfermagem durante as aulas práticas do curso, pode interferir na sua identidade pessoal enquanto sujeitos com características específicas de sua sexualidade. Para eles, 0 sentido de sexualidade estende-se também em direção à expressão de seu jeito de ser e vivenciar o mundo, por meio da vestimenta, dos enfeites, dos modos de arrumar os cabelos e do relacionamento interpessoal. Por isso, citaram este exemplo como forma de disciplinarização da sexualidade transmitida na formação da enfermeira, nas pequenas e corriqueiras situações da vida, em concordância a outro estudo da área de Enfermagem ${ }^{16}$.

Acredita-se que essa atenção destinada ao que 0 estudante pode ou não usar nas suas vivências práticas compreende uma preocupação com as normas técnicas profissionais, como a questão da higiene, por exemplo, as quais, entende-se, constituem um aspecto fundamental para um cuidado de enfermagem alicerçado em bases científicas. No entanto, acredita-se ser importante um olhar atentivo quando acontece uma exaltação e exacerbação dessa preocupação, o que pode constituir-se em um ritual de neutralização dos corpos sexuados ${ }^{14} \mathrm{e}$ do controle da sexualidade.

Além disso, a questão da assexualização do cuidado pode ser percebida quando os estudantes receberam orientações para tratarem de forma indistinta a sexualidade de homens e mulheres. 0 próximo depoimento traz essa constatação:

A gente é trabalhada para dentro do hospital sermos assexuadas: Vocês vão chegar lá, vão trabalhar com homem e com mulher da mesma forma, sem preconceitos, sem trazer o que tem de dentro de vocês. (S12)

Entende-se que essa busca por um cuidado de enfermagem igualitário, para os diferentes sexos, relacionase à assexualização do sujeito cuidado. Isso implica em uma descaracterização do indivíduo, tanto daquele que cuida quanto 
do que está sendo cuidado. Também reflete a dificuldade de cuidar com ética, respeito e comprometimento, se for desconsiderada uma dimensão da vida que não é apenas biológica, mas especialmente social e cultural.

Outro discurso expressa que, naquele contexto, os estudantes revestem-se de um personagem para participarem das vivências práticas do curso, demonstrando que, fora desses momentos, voltam a viver e expressar sua sexualidade.

Eu acho que muitas vezes a gente tem um personagem quando vai para o hospital, quanto ao se vestir. Chega domingo, são todas tirando o esmalte da unha e na segunda-feira de brincos curtos e cabelo atado, sendo que nos outros dias a gente não é assim, lá fora. (S13)

Dessa forma, é possível refletir que o cuidado de enfermagem, é consubstanciado por uma prática que padroniza o cuidador e, portanto, pouco considera sua individualidade, seus desejos e suas características peculiares, havendo risco de ser esvaziado de criatividade e de sensibilidade.

Nesta linha de pensamento concorda-se com autor da área da enfermagem que afirma que no hospital, local neutro, acrítico e impessoal, a mulher se investe de um personagem, no caso a enfermeira, da qual é esperada uma atuação perfeita; porém, fora desse ambiente ela volta a ser, agir, sentir, expressando sua sexualidade ${ }^{17}$.

A partir de uma perspectiva diferenciada, outra estudante considera que deve ser mantida uma imagem padronizada, como forma de impor respeito e acatar os padrões institucionais. Isso pode ser identificado a seguir:

\section{Eu penso que é interessante padronizar, porque nos ajuda a reafirmar a profissão [...]. Se estiver vestindo branco éóbvio que isso vai impor respeito, porque se está seguindo um padrão que foi instituído pela profissão. (S1)}

Essa abordagem considera a necessidade de um comportamento padronizado do enfermeiro, para que ele seja respeitado por aqueles com quem se relaciona. Percebe-se que essa preocupação com o respeito, por meio da utilização de um uniforme, pode estar intrinsecamente relacionada à questão de poder vinculada ao exercício da sexualidade. Além disso, quando os estudantes passam a utilizar esse comportamento como mecanismo de defesa, podem deixar de prestar um cuidado integral ao paciente, realizando-o de forma fragmentada e assexuada ${ }^{18}$.

Em geral, acredita-se que essas conformações em relação à sexualidade se encontram assim estruturadas e viabilizadas no cuidado de enfermagem, como resultado de valores e normas sociais construídos culturalmente na socialização primária do indivíduo e reforçadas na formação acadêmica. Desse modo, é necessário deixar de falar da sexualidade por meio do silêncio, da preocupação excessiva com o rigor da postura e do currículo oculto ${ }^{15}$.

Assim, tem-se a expectativa de que este estudo possa acenar para reflexões que vislumbrem a importância de discutir essa temática na formação acadêmica do enfermeiro. Acreditase que a sexualidade, ao ser tratada de forma limitada e superficial, aparecendo apenas em alguns momentos isolados da formação, pode gerar um cuidado de enfermagem que assexualiza os sujeitos envolvidos e, consequentemente, promover sentimentos negativos na sua vivência, tais como constrangimento, vergonha, culpa, medo, insegurança, entre outros.

\section{CONSIDERAÇÕES FINAIS}

A partir do contexto analisado, observa-se que, para aquela realidade, a sexualidade na formação acadêmica do enfermeiro é tratada a partir de um caráter de eventualidade e informalidade, aparecendo associada ao ensino de algumas técnicas isoladas, em algumas atividades complementares da graduação e nos grupos de pesquisa. Quanto à abordagem do tema, esta se direciona a um enfoque de neutralidade, de proibições e de assexualização, expressada pelo controle comportamental e sobre os modos de vestir dos estudantes. A questão da assexualização do cuidado também pode ser elucidada nas orientações para um tratamento indistinto da sexualidade de homens e mulheres.

Desse modo, reforça-se que a sexualidade precisa ser tratada como assunto de estudo na enfermagem e como fenômeno inerente a todo o ser humano. Nesse sentido, acreditase ser necessário gerar espaços de discussão e reflexão que tratem não apenas da sexualidade do sujeito cuidado, mas, também, dos estudantes de Enfermagem. Pensa-se que estes, quando se compreendem como seres sexuados e percebem 0 outro como tal, têm a possibilidade de sentir e produzir prazer no cuidado enfermagem, despindo-se de preconceitos e tabus que podem perpassar esse momento.

Outra consideração relevante diz respeito à abordagem dessa temática ser estendida aos docentes do curso de graduação em Enfermagem, no qual o estudo foi realizado, considerando a importância de que todos os envolvidos com o processo de ensino-aprendizagem possam lançar esse olhar singular para a temática. A compreensão da sexualidade pelos docentes possibilita a eles não apenas romper com a cultura do silêncio e desvelar essa temática na formação acadêmica do enfermeiro, mas, também, tratar essa questão para além dos limites da interdição, rompendo com tabus e preconceitos. Isso viabiliza o desvelamento dessa dimensão humana no cuidado de enfermagem e possibilita que estudantes e docentes a vivenciem de forma mais tranquila, sensível e criativa nesse momento, possibilitando a qualificação do cuidado prestado. 
Pondera-se, ainda, a possibilidade de que ela seja trabalhada de modo transversal no cenário da formação acadêmica, pois se configura como uma temática que permeia todas as áreas. Sendo assim, pode-se recomendar que a sexualidade seja abordada a partir da realidade vivenciada pelos estudantes, podendo ser utilizadas algumas estratégias de ensino, entre elas as situações-problema, grupos de sentimentos, leitura de artigos científicos que abordem esse assunto, filmes e oficinas didáticas. Enfim, espaços que sejam propulsores da sensibilidade e da criatividade do estudante.

Ademais, não se teve a pretensão, com esta investigação, de esgotar a temática em estudo, sendo considerada importante a percepção de novos olhares sobre ela. Acredita-se que foi possível contribuir para reflexões singulares acerca da sexualidade na formação acadêmica do enfermeiro, o que se viabilizou tanto a partir daquilo que foi dito pelos estudantes quanto do que tenha sido por eles mantido velado.

\section{REFERÊNCIAS}

1. Ressel LB. Vivenciando a sexualidade na assistência de enfermagem: um estudo na perspectiva cultural [tese de doutorado]. São Paulo(SP): USP; 2003.

2. Figueiredo NMA, Carvalho V. O corpo da enfermeira como instrumento de cuidado. Rio de Janeiro: Revinter; 1999.

3. Sehnem GD. Percepções culturais de estudantes de enfermagem acerca da sexualidade: 0 dito e o velado [dissertação de mestrado]. Santa Maria(RS): Departamento de Enfermagem/Universidade Federal de Santa Maria; 2009.

4. Westphal MF, Bógus CM, Faria MM. Grupos Focais: experiências precursoras em programas educativos em saúde no Brasil. Bol. Oficina Sanit. Panam. 1996; 120(6): 472-81.

5. Minayo MCS. 0 desafio do conhecimento: pesquisa qualitativa em saúde. $11^{\circ}$ ed. São Paulo: Hucitec-Abrasco; 2008.

6. Dall'agnol CM, Trench MH. Grupos focais como estratégia metodológica em pesquisas na enfermagem. Rev. gaúch. enferm. 1999 jan; 20(1): 525.

7. Ressel LB, Beck CLC, Gualda DMR, Hoffmann IC, Silva RM da, Sehnem GD. 0 uso do grupo focal em pesquisa qualitativa. Texto \& contexto enferm. 2008 out/dez; 17(4): 779-86.

8. Ministério da Saúde (BR). Conselho Nacional de Saúde. Comissão Nacional de Ética em Pesquisa. Resolução n 196, de 10 de outubro de 1996: diretrizes e normas regulamentadoras de pesquisa envolvendo seres humanos. Brasília(DF): [Conselho Nacional de Saúde]; 1996.
9. Ferreira MA, Figueiredo NMA. Expressão da sexualidade do cliente hospitalizado e estratégias para o cuidado de enfermagem. Rev. bras. enferm. 1997; 50(1): 17-30.

10. Alencar RA, CiosakSI, Bueno SMV. Formação do acadêmico enfermeiro: necessidade da inserção curricular da disciplina de sexualidade humana [periódico na internet]. 2010 set [citado 2012 jul 10]; 9(2): [aprox.10 telas]. Disponivel em: http://www.objnursing.uff.br/index.php/nursing/ article/view/j.1676-285.2010.2991/669

11. Souto MD, Souza IEO. Sexualidade da mulher após a mastectomia. Esc Anna Nery. 2004 dez; 8(3): 402-10.

12. Ribeiro MO. A sexualidade segundo Michel Foucault: uma contribuição para a enfermagem. Rev. Esc. Enferm. USP. 1999 dez; 33(4): 358-63.

13. Moreira MRC, Santos JFFQ. Entre a modernidade e a tradição: a iniciação sexual de adolescentes piauienses universitárias. Esc Anna Nery. $2011 \mathrm{jul} / \mathrm{set}$; 15(3): 558-66.

14. Sobral VRS. A purgação do desejo: memórias de enfermeiras [tese de doutorado]. Rio de Janeiro(RJ): UFRJ; 1994.

15. Pereira AL. Sexuality in care: conflicting experiences of nursing students. Rev. pesqui. cuid. fundam. 2009 set/dez; 1(2): 326-34.

16. Lunardi VL. Repensando a formação da enfermeira. Rev. enferm. UERJ. 1994 out; 2(2): 221-4.

17. Ressel LB, Gualda DMR. A sexualidade invisível ou oculta na enfermagem? Rev. Esc. Enferm. USP. 2002 mar; 36(1): 75-9.

18. Muroya RL, Auad D, Brêtas JRS. Representações de gênero nas relações estudante de enfermagem e cliente: contribuições ao processo de ensinoaprendizagem. Rev. bras. enferm. 2011 jan/fev; 64(1): 114-22. 